clinicians can help individual patients by buffering the effects of structural violence and oppression.

Health-equity advocate Nashira Baril recently noted that "simply accommodating people in systems that were never designed for their survival is inherently inequitable. We must understand how things got this way and explicitly address the systemic imbalance of power and advantage in our approaches to health equity." ${ }^{5}$ It is admittedly difficult to accomplish this aim in the typical clinical setting, but clinicians are not powerless. As part of dedicated interprofessional teams, with institutional support and resources, clinicians can take action that ameliorates the effects of densely woven patterns of disadvantage. Policy change can occur at any level, and downstream policies affect the lives of the most disadvantaged patients. We can strive to treat and heal migrants like Mr. V. by attempting to remediate the structural violence affecting their lives, rather than by exacerbating it through our systems of care.

Disclosure forms provided by the authors are available at NEJM.org.

From the Johns Hopkins Berman Institute of Bioethics and the Esperanza Center Health Clinic - both in Baltimore (Z.D.B.); and the Center for Bioethics and Humani- ties, University of Colorado Anschutz Medical Campus, Denver (D.S.G.).

1. Wolff J, de-Shalit A. Disadvantage. New York: Oxford University Press, 2007.

2. Wolff J. Disadvantage, risk and the social determinants of health. Public Health Ethics 2009;2:214-23 (https://academic.oup .com/phe/article-abstract/2/3/214/1460841).

3. Powers M, Faden R. Social justice: the moral foundations of public health and health policy. New York: Oxford University Press, 2006.

4. Gee GC, Ford CL. Structural racism and health inequities: old issues, new directions. Du Bois Rev 2011;8:115-32.

5. Baril N. When "upstream" public health efforts fall short. Human Impact Partners. February 15, 2019 (https://medium.com/@ HumanImpact_HIP/when-upstreampublic -health-efforts-fall-short-3297dca3c47).

DOI: 10.1056/NEJMp1902966

Copyright (c) 2019 Massachusetts Medical Society.

\title{
Parenting during Graduate Medical Training - Practical Policy Solutions to Promote Change
}

Debra F. Weinstein, M.D., Christina Mangurian, M.D., and Reshma Jagsi, M.D., D.Phil.

Dhsicians have long grappled with the challenge of integrating professional and non-workrelated responsibilities, but this tension demands renewed scrutiny amid growing concerns about physician burnout. Work-life integration is notoriously elusive for graduate medical trainees; residency and fellowship training have historically been all-encompassing. Parenting during clinical training involves particularly difficult challenges. As a substantial number of residents and fellows become parents, their struggles highlight the need for systemic solutions.

Some of the problems faced by trainees with children are predictable, such as sleep deprivation compounded with a newborn at home, lack of accessible and affordable child care that aligns with trainees' work hours, and geographic distance from extended family who could otherwise provide support. Other challenges are less obvious but pervasive, including worry that taking parental leave will prolong training or limit career options, guilt about "dumping" work on colleagues, and concern about being regarded as less committed to medicine than colleagues without children. For childbearing mothers, such stresses are compounded by the physical demands of pregnancy and nursing.

Graduate medical education (GME) program directors strive to support trainee-parents amid multiple constraints. Provision of parental leave is constrained by hospitals' reliance on residents to deliver care and the need to comply with work-hour regulations both of which limit scheduling flexibility. Programs must also ensure that trainees receive comprehensive education and fulfill board-certification requirements, which may include achieving specific case-log quotas. Assessing residents' readiness for practice can also be more difficult when family leave reduces opportunities for observation. Finally, efforts to support family leaves can spur equity concerns among trainees.

Program directors are often left to navigate these obstacles without resources or established policies. A recent study revealed that about half of leading teaching hospitals lack an institutionwide parental-leave policy for residents. ${ }^{1}$ Absent such policies, program directors must navigate the expectations of trainees, faculty members, and department chairs, as well as societal norms, 
Recommendations for Supporting Parenting during GME.*

National oversight organizations

Establish a minimum of 6 weeks of paid leave for all GME trainees, with an intent to move toward 12 weeks

Abandon requirements for making up time and for minimum numbers of cases or procedures in favor of competency assessments

Track and report national data related to parenting during GME

Facilitate institutional development of part-time training options

\section{Sponsoring institutions}

Ensure that institution-level policies address parental leave

Extend 12 weeks of leave provided under FMLA to all trainees

Continue full salary for at least 6 weeks of family leave

Ensure sufficient staffing to protect trainees from negative effects when colleagues are on leave

Facilitate access to child care and lactation facilities

Cultivate cross-specialty trainee parenting collaboratives

Individual residency and fellowship programs

Clarify implications of parental leave for applicants and trainees

Develop creative pilots that will enhance flexibility for trainee-parents

* FMLA denotes Family and Medical Leave Act, and GME graduate medical education.

to create their own programwide policy or, worse, resort to negotiating parental leave on an individual basis. Case-by-case negotiations are especially precarious, given the lack of sufficient staffing to insulate other trainees from the effects of their colleagues' leaves.

Certifying boards add further complexity by setting seemingly arbitrary thresholds for the amount of time trainees must make up after a leave, which vary by specialty. ${ }^{2}$ Two of us highlighted this problem more than a decade ago, ${ }^{3}$ and it remains a substantial obstacle. Delaying graduation to accommodate makeup time creates havoc for trainees seeking jobs and, particularly, for those continuing on to fellowships that operate on the standard academic cycle. Such requirements also pose important logistic problems - especially for small programs that lack sufficient case volume or faculty to accommodate trainees beyond their planned graduation date.
A substantial number of trainees become parents during residency or fellowship programs, amid increasing expectations that both parents take a leave. We believe that structural changes are needed. Steps to support traineeparents could be taken at the national, institutional, and program levels (see table).

First, we call on GME oversight organizations to develop a unified, 21st-century approach to parental leave. The Accreditation Council for Graduate Medical Education (ACGME) recently mandated greater transparency regarding parental-leave policies, requiring that relevant information be provided to applicants and included in trainee contracts. Trainees must also be given "timely notice of the effect of leave(s)" on their ability to complete their program and become eligible for board certification. ${ }^{4}$

Such requirements represent important progress, but we believe that standards should be strengthened to ensure that in- stitutions provide paid leave to all parents (distinct from postpartum medical leave, when needed). Twelve weeks of paid leave, as supported by the American Academy of Pediatrics, ${ }^{5}$ would benefit both parents and children, but 6 weeks could be established as a more feasible initial step.

We also advocate that specialty boards abandon requirements that trainees make up approved absences. In an era of competencybased education, on-time graduation should be allowed after parental or other approved leave as long as trainees are deemed competent for independent practice. Special tracks involving truncated clinical training (such as the American Board of Internal Medicine clinician-investigator pathway) already rely on assessment methods to affirm readiness for practice. Eliminating quotas for procedures or other training activities in favor of competency-based assessments would also be appropriate.

In addition, we recommend that the ACGME, the American Board of Medical Specialties (ABMS), and GME-sponsoring organizations cooperatively track and report aggregated data related to parenting during GME. The number and frequency of births and adoptions; the association between parenting and trainees' educational experiences and duration, clinical assessments, and academic accomplishments; and the influence of specific policies and resources on trainee well-being and on costs and logistics for teaching hospitals can be used to inform best practices and resource planning. The ACGME and ABMS could also collaborate on facilitating institutional development of part-time GME tracks for train- 
ees seeking a less-intensive professional commitment while building a family.

Second, we urge teaching institutions to promulgate familyfriendly policies for trainees and to facilitate access to parenting resources. Until national GME policies include specific parentalleave provisions, written policies should be implemented at the institutional level, rather than by individual programs, to prevent programs with more intensive patient-coverage demands or fewer resources from providing substandard benefits. Codifying 12 weeks of parental leave as institutional policy is important because the Family and Medical Leave Act, which guarantees this benefit, has a 12-month employment-eligibility threshold, thus effectively excluding new trainees. In addition, specifying the duration of paid leave in institutional policies places responsibility for funding these leaves on institutions, rather than on individual programs, and ensures parity throughout specialties.

Providing sufficient staffing to cover resident absences - without placing additional burden on other residents - is another institutional responsibility that can be accomplished by creating deliberate redundancy in resident staffing or funding shortterm coverage by other clinicians or moonlighting trainees.

Institutions could also support trainee-parents by providing access to affordable, nearby child care and backup care and, ideally, space where children can visit briefly with an on-call parent. Allowing regular breaks for nursing mothers and providing convenient lactation facilities (equipped with refrigerators, as well as computers to facilitate multitasking) are essential to enable breastfeeding. Teaching institutions could help cultivate cross-specialty collaboratives for trainee-parents to facilitate information sharing, mutual support, and practical solutions such as shared child care. Making these additional investments will be extremely difficult for many teaching hospitals facing serious financial constraints, but we believe that such initiatives should be prioritized and used as opportunities for innovation.

Finally, it is important for GME programs to provide trainees with explicit information and thoughtful guidance about integrating parenting and training responsibilities. Clarifying the implications of parental leave in more detail than the ACGME requires - including which rotations or clinical experiences must be made up and which can be omitted, what schedule adjustments are feasible to accommodate pregnant or postpartum residents, and whether "work-from-home" elective rotations are possible - will help trainees make important life decisions and help applicants choose training programs.

Individual GME programs can also develop creative pilots. Examples might include policies that allow trainees to take paid leave on an intermittent or part-time basis. Opportunities for shared residency positions might also be explored.

Family-friendly national standards, transparent local policies, and structural resources are all critical to better supporting traineeparents. Financial investments should yield ample rewards by promoting trainee recruitment and, more important, by reducing stress and burnout among a vulnerable group of physicians - benefiting not only them, but also their children, their teams, and their patients.

Disclosure forms provided by the authors are available at NEJM.org.

From the Department of Medicine, Massachusetts General Hospital, the Office of Graduate Medical Education, Partners HealthCare, and Harvard Medical School - all in Boston (D.F.W.); the Department of Psychiatry, Weill Institute for Neurosciences, University of California, San Francisco, San Francisco (C.M.); and the Department of Radiation Oncology and Center for Bioethics and Social Sciences in Medicine, University of Michigan, Ann Arbor (R.J.).

1. Magudia K, Bick A, Cohen J, et al. Childbearing and family leave policies for resident physicians at top training institutions. JAMA 2018;320:2372-4.

2. Varda BK, Glover M IV. Specialty board leave policies for resident physicians requesting parental leave. JAMA 2018;320:2374-7.

3. Jagsi R, Tarbell NJ, Weinstein DF. Becoming a doctor, starting a family — leaves of absence from graduate medical education. N Engl J Med 2007;357:1889-91.

4. ACGME institutional requirements. Chicago: Accreditation Council for Graduate Medical Education, July 2018 (https://www .acgme.org/Portals/0/PFAssets/Institutional Requirements/000InstitutionalRequirements 2018.pdf?ver=2018-02-19-132236-600).

5. Major pediatric associations call for congressional action on paid leave. Chicago: American Academy of Pediatrics, March 20, 2015 (https://www.aap.org/en-us/about-the -aap/aap-press-room/pages/FAMILYLeaveAct .aspx).

DOI: 10.1056/NEJMp1904721

Copyright (C) 2019 Massachusetts Medical Society. 